\title{
Relationship Between Non-Point Source Pollution and Korean Green Factor
}

\author{
Seung Chul Lee ${ }^{1}$, In-Hyeok Park ${ }^{1}$, Byung Sik Kim ${ }^{2}$, and Sung Ryong $\mathrm{Ha}^{1, *}$ \\ ${ }^{1}$ Department of Urban Engineering, Chungbuk National University, Chungbuk, Republic of Korea \\ ${ }^{2}$ Department of Urban and Environmental Disaster Prevention Engineering, Kangwon National University, Gangwon-Do, \\ Republic of Korea
}

Received 31 August 2014, revised 10 November 2014, accepted 10 November 2014

\begin{abstract}
In determining the relationship between the rational event mean concentration (REMC) which is a volume-weighted mean of event mean concentrations (EMCs) as a non-point source (NPS) pollution indicator and the green factor (GF) as a low impact development (LID) land use planning indicator, we constructed at runoff database containing 1483 rainfall events collected from 107 different experimental catchments from 19 references in Korea. The collected data showed that EMCs were not correlated with storm factors whereas they showed significant differences according to the land use types. The calculated REMCs for BOD, COD, TSS, TN, and TP showed negative correlations with the GFs. However, even though the GFs of the agricultural area were concentrated in values of 80 like the green areas, the REMCs for TSS, TN, and TP were especially high. There were few differences in REMC runoff characteristics according to the GFs such as recreational facilities areas in suburbs and highways and trunk roads that connect to major roads between major cities. Except for those areas, the REMCs for BOD and COD were significantly related to the GFs. The REMCs for BOD and COD decreased when the rate of natural green area increased. On the other hand, some of the REMCs for TSS, TN, and TP were still high where the catchments encountered mixed land use patterns, especially public facility areas with bare ground and artificial grassland areas. The GF could therefore be used as a major planning indicator when establishing land use planning aimed at sustainable development with NPS management in urban areas if the weighted GF values will be improved.
\end{abstract}

Key words: NPS management, LID, GF, EMC, REMC

Citation: Lee, S. C., I. H. Park, B. S. Kim, and S. R. Ha, 2015: Relationship between non-point source pollution and Korean green factor. Terr. Atmos. Ocean. Sci., 26, 341-350, doi: 10.3319/TAO.2014.11.10.01(Hy)

\section{INTRODUCTION}

Through urban population concentration, urbanization has aggravated environmental quality over the past few centuries. The ever increasing impervious surface areas produced by urbanization cause increasing non-point source (NPS) pollution in Korea. NPS pollution makes up about $69.3 \%$ on average of the total pollution loads discharged from 4 major watersheds in 2010. NPS pollution is difficult to control and analyze its runoff characteristic because the pollutants are generated and diffused everywhere. This is referred to as the uncertainty of NPS pollution. Numerous researches have been conducted in the field of monitoring data collection (Kim and Lee 2005; Lee et al. 2010, 2012), runoff characteristic analysis (Kim et al. 2003; Lee et al.

\footnotetext{
* Corresponding author

E-mail: simplet@chungbuk.ac.kr
}

2011b) and NPS pollution influence factors (Park and Park 2004; Yoon et al. 2010; Lee et al. 2012) in many cities of Korea to reduce the uncertainty of NPS pollution. Low impact development (LID) has been recently introduced in Korea. LID is a sustainable development concept to reduce surface runoff and NPS pollution through preliminary land use planning using natural green cover to match pre-development conditions (PGC 1999; Coffman 2002).

From the urban planning field viewpoint rapid urbanization brings with it increasing impervious areas that replace natural land. The development scale and its limitations were only regulated by planning indicators that do not consider environmental quality. Urban planning began to consider environmental quality when the sustainable development concept was introduced (Choi and Kwan 2009). A green factor (GF), one of the planning indicators, was established as a means of planning sustainable development to solve urban 
ecological problems (Kim et al. 2006). The existing related indicators are the Biotope flaechen faktor (BFF, Berlin), the Seattle green factor (SGF, Seattle), and the Green area factor (GAF, Malmo). These indicators are similar in the sense that they apply weights for calculating the area and express a percentage of land area. The GF value application standard for land use planning already exists in the city of Seoul (Kim and Moon 2004). The main aim of using the GF was to secure a certain amount of green cover and minimize sealed or paved surfaces (Kim et al. 2006). However, the ecological and environmental effect of the GF is under investigation.

This research was conducted to determine a relationship between the NPS pollution and GF for sustainable NPS management using LID land use planning. The objectives of this research were (1) to examine the runoff characteristics of NPS pollution according to the storm factors and land use; and (2) to come up with a correlation between the GF and NPS pollution.

\section{MATERIALS AND METHODS}

\subsection{Data Collection}

The Korean runoff database was built in this research before analyzing the storm runoff characteristics of NPS pollution. Observed runoff data were collected from original sources citations published in referred journals, research reports and theses from 2001 - 2012. In total, 107 study sites were included in the database. Figure 1 shows the distribution of monitored sites in the four major rivers of Korea. Sixty-seven sites were in the Han-river watershed; 21 in the Nakdong-river watershed; 13 in the Geum-river watershed; and 6 in the Youngsan-river watershed.

The land use of these sites were classified using 9 types of land use, such as agriculture, grassland, forest, traffic, residential, industrial, business, recreational facilities and public facilities areas according to the land cover classification standard made by the Ministry of Environment (MOE). The monitored runoff data classified by land use types are briefly presented in Table 1 .

Runoff data from 1483 rainfall events were collected from 107 different monitored sites from the 19 references in the database. The collected runoff data were monitored in each rainfall event that occurred from May to September. Each rainfall event differed in storm factors, such as total rainfall, average rainfall intensity, duration time, and antecedent dry day (ADD). Sampling data were collected from the catchment outlet beginning at storm water runoff initiation and ending when each storm event stopped. Five indicators (e.g., TSS, BOD, COD, TN, and TP) were determined for data analysis.

\subsection{Data Analyses}

An event mean concentration (EMC) was selected as the predominant method for reporting runoff event water quality to determine the representative pollutant concentration from the hourly pollutant concentration data variation from the selected publications (Charbeneau and Barrett 1998). The EMC referred to the weighted EMCs calculated to estimate the NPS pollution runoff characteristics using storm factors. The EMC can be computed as the total pollutant mass divided by the total runoff volume in event duration. The EMC calculation method is shown in Eq. (1).

$$
\operatorname{EMC}\left(\mathrm{mg} \mathrm{L}^{-1}\right)=M / V=\sum_{t=0}^{t=T} C(t) \cdot Q(t) / \sum_{t=0}^{t=T} Q(t)
$$

where EMC is the event mean concentration; $M$ is a total pollutant mass in an event $(\mathrm{g}) ; V$ is the total runoff volume $\left(\mathrm{m}^{3}\right)$; $C(t)$ is the time variable pollutant concentration $\left(\mathrm{mg} \mathrm{L}^{-1}\right) ; Q(t)$

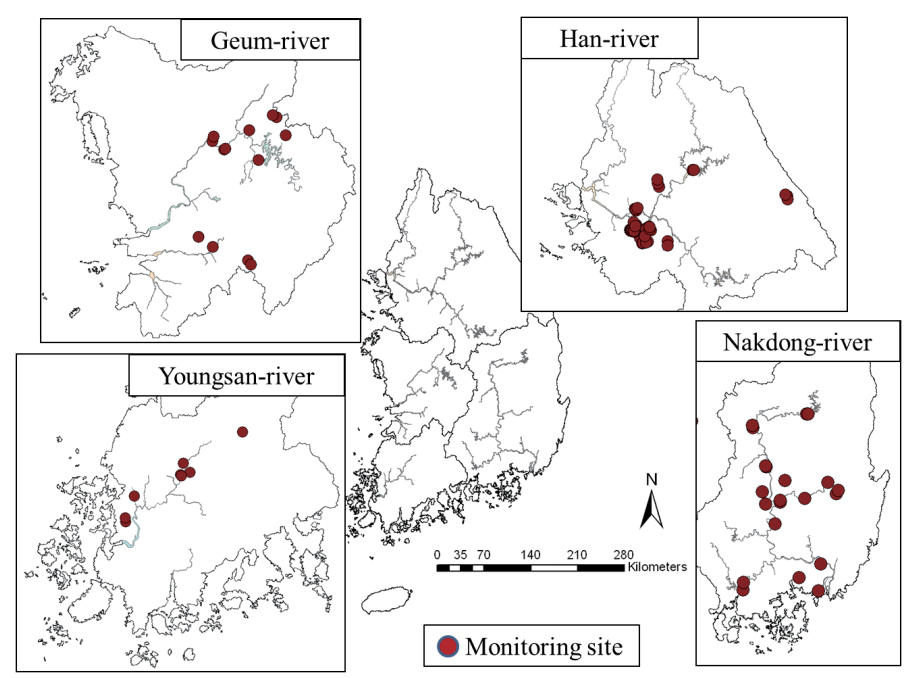

Fig. 1. Spatial distribution of monitored sites in Korea. 
Table 1. Summary of Korean runoff database built in this research.

\begin{tabular}{c|ccc}
\hline Land use type & No. of Rainfall events & No. of Monitored sites & References \\
\hline Traffic & 300 & 24 & \\
Industrial area & 85 & 9 & Lee and Kim (2001); Choi and Shin (2002); Kim et al. \\
Agriculture & 451 & 37 & (2002); Kim and Lee (2005); Kim (2008); MOE (2008); \\
Forest area & 136 & 7 & Choi et al. (2009); Go et al. (2009); Lee and Lee (2009); \\
Business area & 67 & 5 & Park et al. (2009); GRERC (2011); HRERC (2011); Lee et \\
Residential area & 154 & 14 & al. (2011a); NRERC (2011); Shin (2011); YRERC (2011); \\
Public facilities & 128 & 4 & Joo (2012); Jung and Kim (2012); Kang (2012) \\
Grassland area & 126 & 6 & \\
Recreational facilities & 36 & 2 & \\
\hline Total & 1483 & 107 & \\
\hline
\end{tabular}

is the runoff flow rate discharged at time $t\left(\mathrm{~m}^{3} \mathrm{~min}^{-1}\right)$.

Determining the representative pollutant concentration from the land use is potentially problematic because one set of land use data is coupled with a variety of EMC values. The most commonly used method to estimate the central EMC distribution value is the site mean concentration (SMC) computed as the arithmetic mean of the EMCs. However, the minimum number of EMCs and their statistical distribution are required to find a reliable SMC as a representative mean value (Mourad et al. 2005).

The rational event mean concentration (REMC) which is similar to the EMC calculation method was selected in this research as shown in Eq. (2).

$\operatorname{REMC}\left(\mathrm{mg} \mathrm{L}^{-1}\right)=\sum_{i=1}^{i=I} M(i) / \sum_{i=1}^{i=I} V(i)$

where REMC is the regional event mean concentration; $M(i)$ is the total pollutant mass ( $\mathrm{g}$ ) of the $i$ th storm event; $V(i)$ is the total volume $\left(\mathrm{m}^{3}\right)$ of $i$ th storm event; $I$ is the total number of EMCs at one specific site. REMC is a volume-weighted EMC mean for one specific site for different storm runoff volumes. This is a valid approach where a significant correlation exists between the EMC and runoff volume (Mourad et al. 2005) and produces the most accurate long-term load estimates (May and Sivakumar 2012).

\subsection{GF}

The GF was basically calculated as the ratio of the surface area, which has a natural circulation function, to the whole catchment area. The MOE has provided criteria to distinguish the types of land cover and weights by establishing guidelines for GF estimation (MOE 2011). The detailed computation method process for GF using land use data from 107 sites is as follows. A detailed land cover data is first extracted utilizing aerial images after classifying the land use type for the target catchment using the existing land use map. It is then classified using the natural green area and artificial surface area. The artificial surface area was multiplied by the green weighted value, and added with the natural green area. The GF is finally calculated as this combined area divided by the total catchment area, shown as the following Eq. (3).

$\mathrm{GF}=\left[\mathrm{NGA}+\sum_{j=1}^{j=J} A S A(j) \cdot W v(j)\right] / \mathrm{TCA} \times 100$

where, GF is a green factor; TCA is the total catchment area $\left(\mathrm{m}^{2}\right)$; NGA is the natural green area covered by vegetation with natural soil $\left(\mathrm{m}^{2}\right) ; A S A(j)$ is the $j$ land cover type for the artificial surface area $\left(\mathrm{m}^{2}\right) ; W v(j)$ is the $j$ type of green weighted value. This weighted value is assigned to different surface types varying from 0 for paved impervious areas to 1 for naturally vegetated areas in contact with ground water. The calculated GF has a range of 0 - 100 in a certain catchment area. Table 2 is a summary of the green weighted values applied using land cover type in this research.

The GF computation result for the residential area experimental site is shown in Table 3. We compared the GF with the green area rate (GAR) and the pervious area rate (PAR) to describe the GF value characteristics. The computed GF, GAR, and PAR were 16.9, 15.7, and 21.1, respectively. The GAR can be calculated as the percentage of the natural and artificial green areas in the total catchment area. The PAR, which is the opposite meaning of impervious area rate, is the percentage of permeable cover area. The GF can distinguish between the natural green area runoff characteristics from the artificial green area in comparison with the GAR. The GF compared with the PAR can characterize the runoff of paved areas from that of bare ground areas.

\section{RESULTS AND DISCUSSION}

\subsection{Characteristics of Storm Factors and EMCs}

Statistical analysis for storm factors and water quality 
constituents of the established runoff database was conducted. The number of samples, storm factor distribution and EMCs are summarized in Table 4. The number of storm factors and EMC samples are different from each other because these data sets were collected by different references. The mean rainfall, intensity, duration, and ADD values are $37.37 \mathrm{~mm}, 3.93 \mathrm{~mm} \mathrm{hr}^{-1}, 12.30 \mathrm{hr}$, and 5.64 days. The BOD, COD, TSS, TN, and TP values are 12.38, 24.66, 213.98, 5.04 , and $1.03 \mathrm{mg} \mathrm{L}^{-1}$, respectively. High variability is observed in the TSS case $\left[0.30-17812.1 \mathrm{mg} \mathrm{L}^{-1}\right.$, coefficient of variation $(\mathrm{CV})=3.56]$. As a result of skewness and kurtosis for all storm factors and EMCs, all data sets have a positive skewed distribution and are more peaked than the normal distribution.

The number of valid rainfall events data with storm factors and EMCs were 1241. These data sets were used to analyze the correlations between storm factors and EMCs. The Pearson correlation coefficients and confidence values (p-value) results are shown in Table 5. No correlation between storm factors and EMCs were found. In the case of storm factors, total rainfall has a correlation with duration time (correlation coefficient $=0.558, \mathrm{p}$-value $<0.01$ ) There is a significant correlation between BOD and COD of EMCs (correlation coefficient $=0.635$, p-value $<0.01$ ). This

Table 2. Green weighted value according to land cover type.

\begin{tabular}{lc}
\hline \multicolumn{1}{c}{ Land cover type } & Green weighted value \\
\hline Paved cover with artificial soil (e.g., buildings, roads, parking lots etc.) & 0 \\
Natural soil without vegetation (e.g., barrens, fields, and playgrounds etc.) & 0.3 \\
Vegetated cover with artificial soil (e.g., golf courses, cemetery parks, and & 0.7 \\
upper structure of underground parking lots) & 0.8 \\
Agricultural land cover (e.g., paddy and upland fields) & 1 \\
Vegetated cover with natural soil (e.g., natural forest and green areas) & 1 \\
Water with natural soil & \\
\hline
\end{tabular}

Note: Source: $M O E$ (2011).

Table 3. Detailed computation of GF in experimental site.

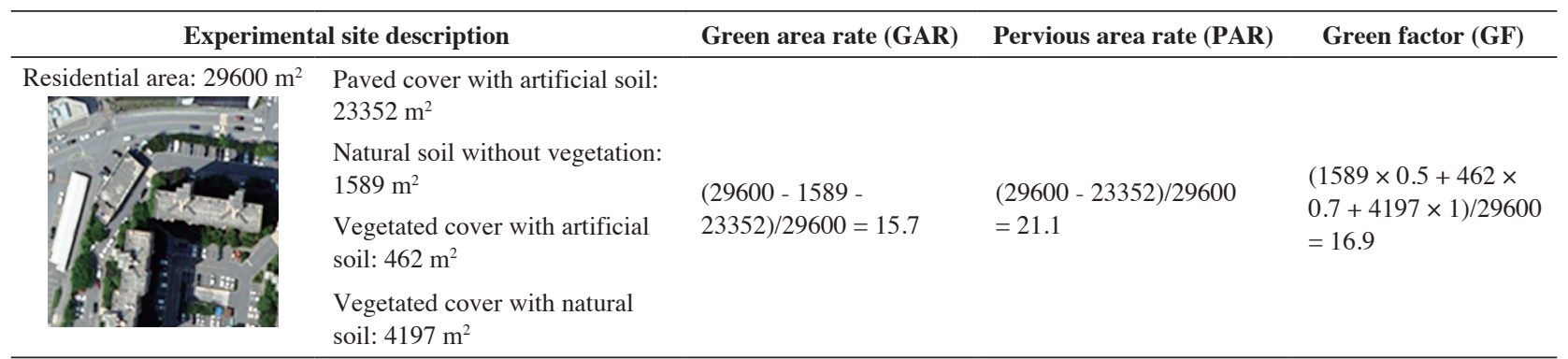

Table 4. Statistical summary of Storm factors and EMCs in the established runoff database

\begin{tabular}{|c|c|c|c|c|c|c|c|}
\hline & $\mathbf{N}^{(1)}$ & Mean & Min & Max & $\mathbf{C V}^{(2)}$ & Skew $^{(3)}$ & Kurt $^{(4)}$ \\
\hline Rainfall (mm) & 1387 & 37.37 & 0.30 & 508.7 & 1.27 & 4.18 & 27.97 \\
\hline Intensity $\left(\mathrm{mm} \mathrm{hr}^{-1}\right)$ & 1163 & 3.93 & 0.09 & 89.0 & 1.43 & 9.44 & 129.56 \\
\hline Duration (hr) & 1163 & 12.30 & 0.17 & 230.0 & 1.23 & 6.00 & 59.09 \\
\hline $\mathrm{ADD}$ (day) & 1346 & 5.64 & 0.00 & 100.0 & 1.36 & 6.21 & 61.87 \\
\hline $\mathrm{BOD}\left(\mathrm{mg} \mathrm{L}^{-1}\right)$ & 1387 & 12.38 & 0.10 & 300.8 & 1.55 & 5.12 & 47.33 \\
\hline $\mathrm{COD}\left(\mathrm{mg} \mathrm{L}^{-1}\right)$ & 1387 & 24.66 & 0.24 & 761.0 & 1.49 & 7.96 & 123.53 \\
\hline $\operatorname{TSS}\left(\mathrm{mg} \mathrm{L}^{-1}\right)$ & 1387 & 213.98 & 0.30 & 17812.1 & 3.56 & 12.21 & 226.47 \\
\hline $\mathrm{TN}\left(\mathrm{mg} \mathrm{L}^{-1}\right)$ & 1387 & 5.04 & 0.02 & 46.3 & 0.98 & 2.72 & 11.00 \\
\hline $\mathrm{TP}\left(\mathrm{mg} \mathrm{L}^{-1}\right)$ & 1387 & 1.03 & 0.002 & 34.9 & 2.54 & 7.59 & 71.57 \\
\hline
\end{tabular}

Note: (1) Number of samples, (2) coefficient of variation, (3) skewness, (4) kurtosis. 
Table 5. Matrix of the correlation between storm factors and EMCs of NPS pollutants.

\begin{tabular}{|c|c|c|c|c|c|c|c|c|c|}
\hline & Rainfall & Intensity & Duration & ADD & BOD $\left(m g L^{-1}\right)$ & $\operatorname{COD}\left(m g L^{-1}\right)$ & TSS $\left(m g L^{-1}\right)$ & $\mathbf{T N}\left(\mathrm{mg} \mathrm{L}^{-1}\right)$ & $\mathbf{T P}\left(\mathrm{mg} \mathrm{L}^{-1}\right)$ \\
\hline Rainfall & 1 & & & & & & & & \\
\hline Intensity & $0.274 * *$ & 1 & & & & & & & \\
\hline Duration & $0.558^{* *}$ & $-0.119 * *$ & 1 & & & & & & \\
\hline ADD & $-0.105^{* *}$ & $-0.066^{*}$ & -0.038 & 1 & & & & & \\
\hline BOD $\left(\mathrm{mg} \mathrm{L}^{-1}\right)$ & -0.055 & -0.036 & $-0.074 * *$ & 0.044 & 1 & & & & \\
\hline $\operatorname{COD}\left(\mathrm{mg} \mathrm{L}^{-1}\right)$ & $-0.096 * *$ & -0.051 & $-0.101 * *$ & $0.082 * *$ & $0.635^{* *}$ & 1 & & & \\
\hline TSS (mg L L-1) & $0.158^{* *}$ & 0.008 & $0.107 * *$ & -0.037 & $0.089 * *$ & $0.119^{* *}$ & 1 & & \\
\hline $\mathbf{T N}\left(\mathrm{mg} \mathrm{L}^{-1}\right)$ & 0.027 & $-0.105^{* *}$ & $0.078^{* *}$ & 0.037 & $0.217 * *$ & $0.231^{* *}$ & $0.150^{* *}$ & 1 & \\
\hline $\mathbf{T P}\left(\mathrm{mg} \mathrm{L}^{-1}\right)$ & $0.159 * *$ & -0.002 & $0.111^{* *}$ & $-0.088^{* *}$ & $0.462^{* *}$ & $0.361^{* *}$ & $0.205^{* *}$ & $0.317^{* *}$ & 1 \\
\hline
\end{tabular}

Note: *: p-value $<0.05$; **: p-value $<0.01$.

result is different from that found by other researchers who reported rainfall amounts, rainfall intensity and ADD were significantly correlated with various pollutant parameters (Yoon et al. 2010; Lee et al. 2012). This could be caused by the uncertainties of NPS pollutant runoff because of the differences in the total number of monitoring data or the differences in pollutant build-up and wash-off features on various types of land surfaces (Ha and Lee 2008). It is necessary that storm factors and also land use or land cover be considered to reveal the runoff characteristics of NPS pollutants.

\subsection{EMCs of Different Land Use Types}

The EMCs of nine land use types were compared to investigate the NPS pollution of different land use types, as shown in Fig. 2. From the box chart, we can deduce that the pollutant concentrations in the runoff are significantly different for different land use types.

There are lots of human activities and heavy traffic in urbanized areas. For that reason the EMCs of the whole pollutant constituents diffused from urbanized areas such as public and recreational facilities areas, industrial areas, traffic areas, business and residential areas were higher than those from grassland and forest areas. The reason for the lower EMCs in grassland and forest areas is due mainly to the vegetated coverage which has pollutant retention ability. The EMCs of TSS, TN, and TP in agricultural areas were significantly high. There are lots of sediments and manure or compost fertilized on the surface, especially in cultivated upland, and these sediments are then discharged when rainfall occurs.

\subsection{GF and REMC}

The GF and REMC were calculated to analyze the runoff water quality according to the land use characteristics using the runoff database. The GF has a statistical data conversion characteristic from categorical land use data to the continuous data for analysis of the relationship between
NPS pollution and land use. The GF was computed using Eq. (3) as a representative land use value for each site. The calculated GFs distribution is skewed to both sides, especially the ranges $0-20,70-80$, and $90-100$ of GFs are high frequency as shown in Fig. 3, because many existing researchers were focused on NPS runoff monitoring in a single land use category as well as the high rate of paved urban, agricultural, and forest areas in Korea.

In terms of Korean urban planning, land use types in the urban planning area can be divided into urban and nonurban areas. Residential, business, industrial, traffic, public, and recreational facility areas and green areas as well as forest areas as a green area for conservation can be included with the urban area. Agricultural areas can be included in non-urban areas.

Figure 4 shows the calculated REMCs for BOD, COD, TSS, TN, and TP according to the GFs using Eq. (3). As the GF value increased, which means that natural green area increased, the REMCs of the whole pollutant constituents conversely tended to decrease in the urban area. Even though the GFs of the agricultural area are concentrated in the value of 80 like a green area, the REMCs of TSS, TN, and TP are especially high. The main reason is that the greater the cultivated area rate is increases, the higher the concentrations of contaminants such as sediments, nitrogen, and phosphorous discharged (Kim et al. 2003). Moreover, there is little difference in REMC runoff characteristics according to the GFs in some parts of the urban areas such as recreational facilities in suburbs and highways and trunk roads which are connecting roads between major cities. These recreational facilities which are about $60-70$ of the GF values have a high rate of natural land conditions. However, the REMCs for BOD and COD are relatively high due to a large transient population. On the other hand, although highways and trunk roads have 0 - 10 of GFs as the typical paved areas, the REMCs are relatively low because the pollutant source is only an accumulated non-point source pollutant on the roads in the non-urbanized environment. 


\subsection{Relationship Between GF and REMC}

The relationships between the GFs and REMCs in urbanized areas except for agricultural area, recreational facilities and certain parts of traffic areas such as highways and trunk roads were analyzed. Regression analysis was performed to provide a functional relationship between the
GF and REMC (Table 6). The power regression model was the most suitable to illustrate their relationships.

Figure 5 shows the regression analysis results in urban areas. The REMCs for BOD and COD are significantly related with the GFs. The r-squared values are 0.81 and 0.56 respectively (Fig. 5). The REMCs for BOD and COD have the characteristic that their concentrations decrease when
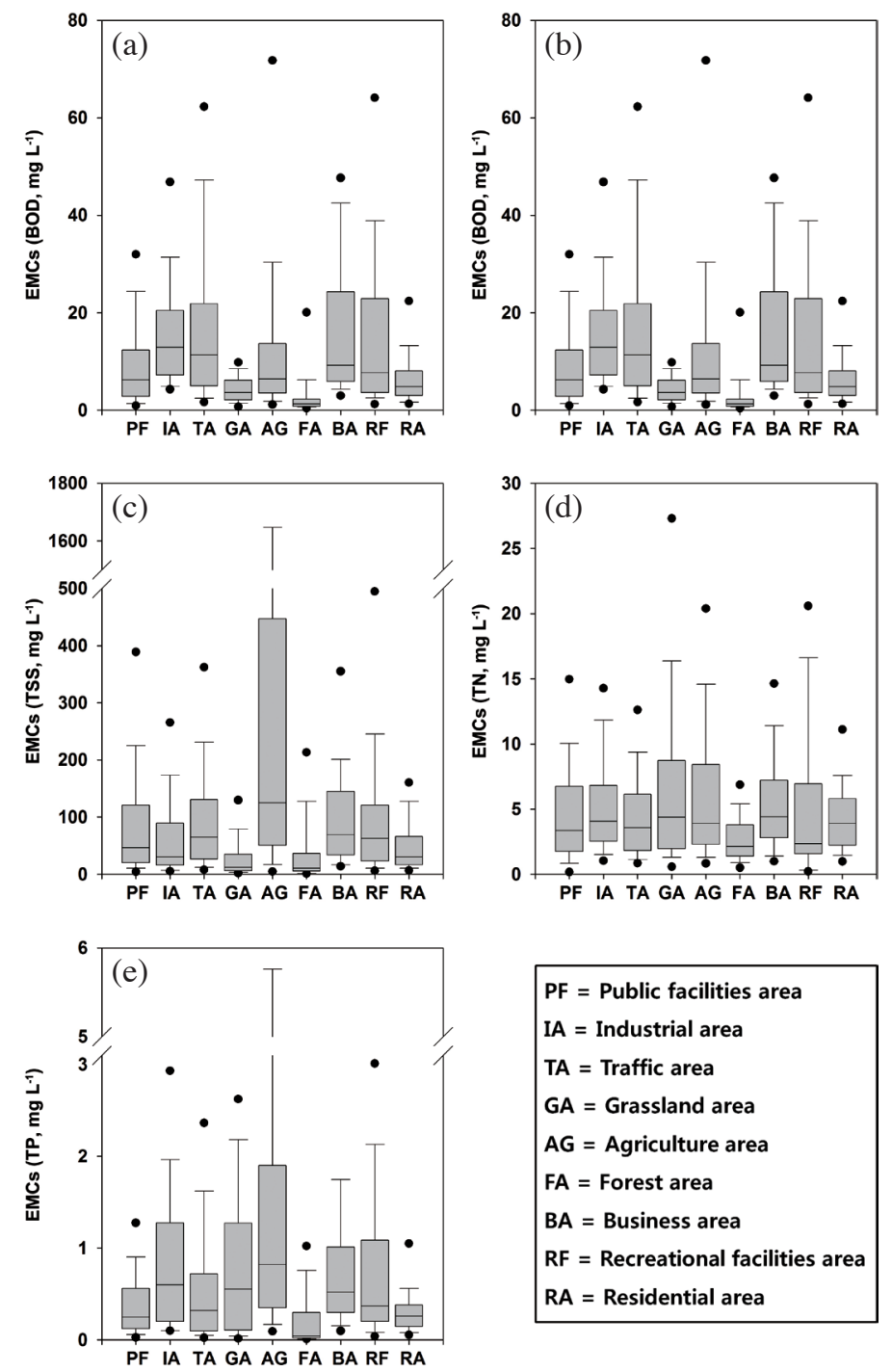

Fig. 2. EMCs of pollutant constituents in different land use types, (a) BOD, (b) COD, (c) TSS, (d) TN, (e) TP.

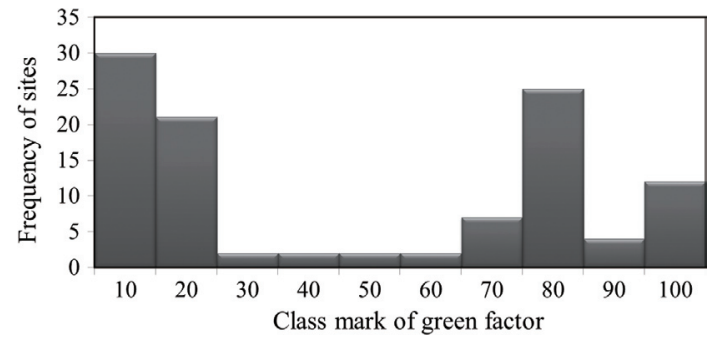

Fig. 3. The frequency distribution of the green factors (GFs) (the total number of sites $=107$ sites). 

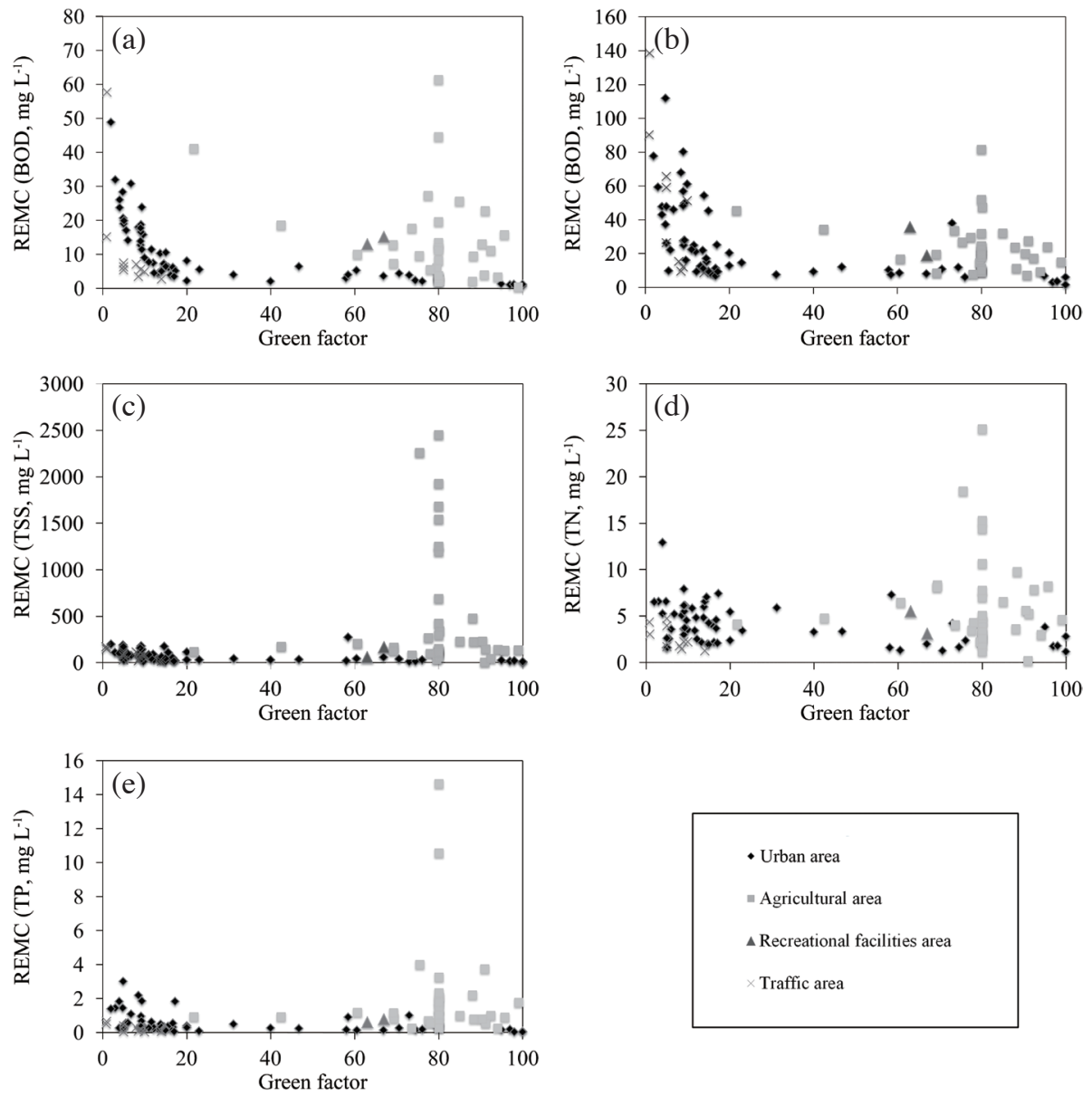

Fig. 4. The distribution of REMCs according to the GFs, (a) BOD, (b) COD, (c) TSS, (d) TN, (e) TP.

Table 6. Regression analysis for relationship between REMCs and GFs.

\begin{tabular}{|c|c|c|c|c|c|c|}
\hline & \multicolumn{2}{|c|}{ Regression models* } & $\mathbf{R}^{2}$ & p-value & $\mathbf{a}$ & b \\
\hline \multirow{4}{*}{ BOD } & Linear & $Y=a+b x$ & 0.340 & 0.000 & 15.892 & -0.188 \\
\hline & Natural logarithm & $\mathrm{Y}=\mathrm{a}+\mathrm{b} \ln (\mathrm{x})$ & 0.648 & 0.000 & 32.215 & -7.665 \\
\hline & Power & $Y=a x^{b}$ & 0.805 & 0.000 & 78.367 & -0.854 \\
\hline & Exponent & $Y=a e^{b x}$ & 0.662 & 0.000 & 14.742 & -0.026 \\
\hline \multirow{4}{*}{ COD } & Linear & $Y=a+b x$ & 0.252 & 0.000 & 37.081 & -0.391 \\
\hline & Natural logarithm & $\mathrm{Y}=\mathrm{a}+\mathrm{b} \ln (\mathrm{x})$ & 0.410 & 0.000 & 67.592 & -14.715 \\
\hline & Power & $Y=a x^{b}$ & 0.563 & 0.000 & 121.082 & -0.680 \\
\hline & Exponent & $\mathrm{Y}=\mathrm{a} \mathrm{e}^{\mathrm{bx}}$ & 0.478 & 0.000 & 32.313 & -0.021 \\
\hline \multirow{4}{*}{ TSS } & Linear & $Y=a+b x$ & 0.134 & 0.005 & 88.501 & -0.719 \\
\hline & Natural logarithm & $\mathrm{Y}=\mathrm{a}+\mathrm{b} \ln (\mathrm{x})$ & 0.206 & 0.000 & 142.401 & -26.274 \\
\hline & Power & $Y=a x^{b}$ & 0.320 & 0.000 & 219.855 & -0.551 \\
\hline & Exponent & $Y=a e^{b x}$ & 0.301 & 0.000 & 77.263 & -0.018 \\
\hline \multirow{4}{*}{$\mathrm{TN}$} & Linear & $Y=a+b x$ & 0.170 & 0.001 & 4.910 & -0.030 \\
\hline & Natural logarithm & $\mathrm{Y}=\mathrm{a}+\mathrm{b} \ln (\mathrm{x})$ & 0.192 & 0.001 & 6.748 & -0.955 \\
\hline & Power & $Y=a x^{b}$ & 0.221 & 0.000 & 7.236 & -0.256 \\
\hline & Exponent & $Y=a e^{b x}$ & 0.232 & 0.000 & 4.508 & -0.009 \\
\hline
\end{tabular}

Note: *: $Y=$ Regional event mean concentration $($ REMC), $x=$ Green factor. 
Table 6. (Continued)

\begin{tabular}{|c|c|c|c|c|c|c|}
\hline & \multicolumn{2}{|c|}{ Regression models* } & \multirow{2}{*}{$\begin{array}{c}\mathbf{R}^{2} \\
0.121\end{array}$} & \multirow{2}{*}{$\begin{array}{c}\text { p-value } \\
0.007\end{array}$} & \multirow{2}{*}{$\frac{\mathbf{a}}{0.743}$} & \multirow{2}{*}{$\begin{array}{c}\mathbf{b} \\
-0.007\end{array}$} \\
\hline \multirow{4}{*}{ TP } & Linear & $\mathrm{Y}=\mathrm{a}+\mathrm{bx}$ & & & & \\
\hline & Natural logarithm & $Y=a+b \ln (x)$ & 0.215 & 0.000 & 1.331 & -0.279 \\
\hline & Power & $Y=a x^{b}$ & 0.348 & 0.000 & 1.693 & -0.572 \\
\hline & Exponent & $Y=a e^{b x}$ & 0.289 & 0.000 & 0.554 & -0.018 \\
\hline
\end{tabular}

(a)

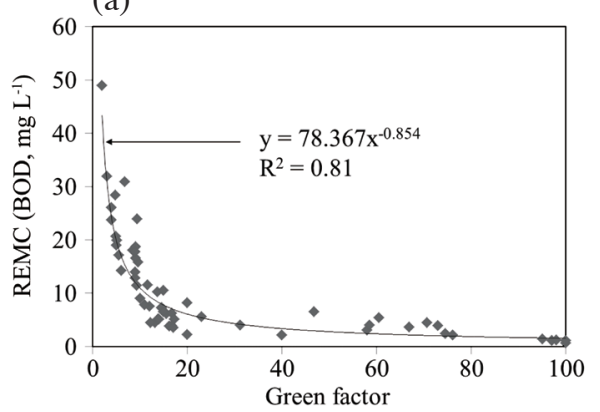

(b)

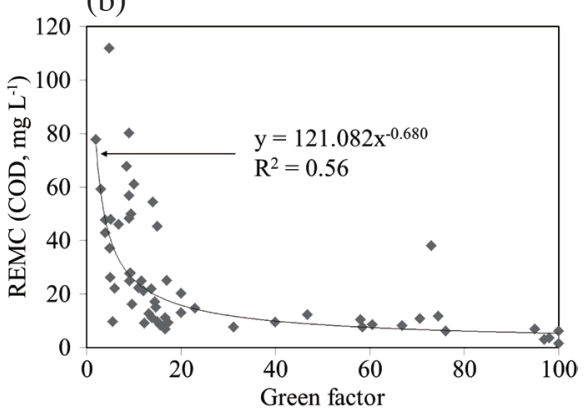

Fig. 5. Relationships between the GFs and REMCs in urban area, (a) BOD, (b) COD.

the rate of natural green area is increased.

The relationships between the GFs and REMCs for TSS, TN, and TP are shown in Table 5. These constituents show negative correlations with the GF when the catchments have a single land use pattern, e.g., a road, a parking lot, a grassland, and forest area. However, some of the REMCs for TSS, TN, and TP are abnormally high as outliers where the catchments have a mixed land use pattern, especially public facilities such as education and park facilities which have some bare ground and artificial grassland areas such as golf courses and cemetery parks. They are required to manage the NPS pollution using natural soil with green areas. Therefore, the public facilities that have point source and open space should apply the LID technique for rainfall runoff and NPS reduction in urban areas.

\section{CONCLUSIONS}

NPS pollution using land use change should be predictable for sustainable land use planning and NPS management. A quantification indicator (e.g., GF) lends scientific objectivity to the NPS control effect (e.g., REMC) when establishing land use planning in urban areas. This research was conducted to find a relationship between the REMC as a NPS pollution indicator for sustainable NPS management and GF as a land use planning indicator for sustainable development. The established Korean runoff database for analyzing this relation contains 1483 rainfall events with storm factors and water quality constituents collected from 107 different experimental catchments in various references.

The statistical analysis result for storm factors and wa- ter quality constituents shows a high variability and these whole sets of data have a positive skewed distribution, and are more peaked than the normal distribution. Significant correlations between storm factors and EMCs for NPS pollutants were not found. It should be difficult to control NPS pollution using storm factors. The EMCs of the whole pollutant constituents diffused from urbanized area were higher than those from grassland and forest areas. The EMCs in agricultural areas were significantly high because there are lots of sediments and manure, especially in the cultivated upland.

The GF and REMC were calculated to analyze the runoff water quality according to the land use characteristic in the 107 runoff database sites. The calculated GFs distribution is skewed to the ranges $0-20,70-80$, and $90-100$ of GFs because many existing researchers were focused on NPS runoff monitoring in single land use areas as well as the high rate of paved urban, agricultural, and forest areas in Korea. The REMCs for BOD and COD have a significantly negative relation with the GFs in urban areas. However, some of the REMCs for TSS, TN, and TP were abnormally high where the catchments have mixed land use patterns, especially public facilities such as education and park facilities which have some bare ground and artificial grassland areas such as golf courses and cemetery parks.

From the results of this research the GF can be used as a major planning indicator when establishing land use planning aimed at sustainable development with NPS management in urban areas. Furthermore, the GF might be one of the LID application standards for public facilities if the weighted values will be improved because the NPS runoff 
characteristics are not applied to the existing green weighted GF values.

Acknowledgements This research was supported by the National Research Foundation of Korea (NRF) under the Korean government [Ministry of Education and Science Technology (MEST)] in 2012 (No.2011-0028914).

\section{REFERENCES}

Charbeneau, R. J. and M. E. Barrett, 1998: Evaluation of methods for estimating stormwater pollutant loads. Water Environ. Res., 70, 1295-1302, doi: 10.2175/106143098X123679. [Link]

Choi, H. S. and Y. H. Kwan, 2009: Improving of planning system for sustainable urban development: Focus on introducing environmental and ecological planning. $J$. Environ. Policy, 8, 27-51.

Choi, J. Y. and C. M. Shin, 2002: Management of Nonpoint Pollution by Reducing Storm Runoff, Report of KEI, 169-210.

Choi, J. Y., S. Y. Lee, and L. H. Kim, 2009: Wash-off characteristics of NPS pollutants from forest landuse. $J$. Kor. Soc. Hazard. Mater., 9, 129-134.

Coffman, L. S., 2002: Low Impact Development: Smart technology for clean water - Definitions, issues, roadblocks, and next steps. In: Strecker, E. W. and W. C. Huber, Global Solutions for Urban Drainage, American Society of Civil Engineers, 1-11, doi: 10.1061/40644(2002)20. [Link]

Geum River Environment Research Center (GRERC), 2011: Research on Long-term Monitoring and BMPs for the Non-point Source Discharge, NIER, Korea, 159-193.

Go, S. H., S. A. Memon, and C. H. Lee, 2009: Characterization of stormwater pollutants and estimation of unit loads for road and parking lot in Gyeongan stream watershed. J. Korean Soc. Water Qual., 25, 689-696.

Ha, S. R. and S. C. Lee, 2008: Reductive characteristics of washed-off pollution loads by best management practices. Water Sci.Technol., 58, 2339-2346, doi: 10.2166/ wst.2008.828. [Link]

Han River Environment Research Center (HRERC), 2011: Research on Long-term Monitoring and BMPs for the Non-point Source Discharge, NIER, Korea, 44-221.

Joo, J. S., 2012: Analysis of the characteristics of non-point pollutant runoff and effects of SWMM-LID in industrial area. Master Thesis, Pusan National University, Korea.

Jung, Y. J. and S. W. Kim, 2012: Characteristics of storm water runoff from urban areas with industrial complex. J. Wetl. Res., 14, 131-137.

Kang, D. G., 2012: Classification of small management basin considering NPS pollution runoff characteristics. $\mathrm{Ph} . \mathrm{D}$. Thesis, Kangwon National University, Korea.

Kim, G. H., Y. C. Kim, D. R. Lee, H. Y. Jung, and J. H.
Yur, 2003: Analysis and estimation of EMC Loads of Rainfall Runoff from Agricultural-Forestry in Korea. J. Kor. Soc. Environ. Eng., 25, 760-770.

Kim, H. S. and S. Y. Moon, 2004: Practical use of biotope surface factor for environmentally friendly urban planning. Proceedings of Annual Conference of AIK, Korea, 523-526.

Kim, H. S., S. Y. Moon, D. H. Jang, and K. H. Lee, 2006: A study on the classification of surface type and it's weight in Biotope-Area-Factor. J. Archit. Inst. Korea, 22, 175-182.

Kim, I. H. and S. H. Lee, 2005: Characteristics of washedoff pollutants and dynamic EMCs in a parking lot and a bridge during storms. J. Korean Soc. Water Qual., 21, 248-255.

Kim, S. S., J. S. Kim, K. Y. Bang, E. M. Gwon, and W. J. Chung, 2002: The Estimation of the Unit Load and Characteristics of Non-Point Source Discharge According to Rainfall in Kyongan Watershed. J. Kor. Soc. Environ. Eng., 24, 2019-2027.

Kim, Y. Y., 2008: Calculation of design capacity of nonpoint pollutants treatment facility using XP-SWMM. Master Thesis, Hanbat National University, Korea.

Lee, H. and S. Lee, 2009: Runoff characteristics of stormwater in small city urban area. J. Kor. Soc. Environ. Eng., 31, 193-202.

Lee, H. W., N. H. Choi, Y. S. Lee, and J. H. Choi, $2011 \mathrm{a}$ : Estimation of pollutants loading from non-point sources based on rainfall event and land use characteristics. J. Kor. Soc. Environ. Eng., 33, 572-577, doi: 10.4491/ KSEE.2011.33.8.572. [Link]

Lee, J. H., S. Park, D. Kim, Y. J. Lee, and M. J. Park, 2012: Long-term Monitoring and Analysis for Discharge Characteristics of Nonpoint Source Pollution by Land Use Types in Geum River Basin. J. Kor. Soc. Hazard. Mitig., 12, 343-350, doi: 10.9798/KOSHAM.2012.12.6.343. [Link]

Lee, J. S. and Y. C. Kim, 2001: Discharge of the diffuse pollutants form small agricultural watersheds during rainstorms and determination of the detention ponds capacity. J. KSCE, 201, 575-588.

Lee, J. Y., H. J. Kim, Y. J. Kim, and M. Y. Han, 2011b: Characteristics of the event mean concentration (EMC) from rainfall runoff on an urban highway. Environ.Pollut., 159, 884-888, doi: 10.1016/j.envpol.2010.12.022. [Link]

Lee, S. C., I. H. Park, J. I. Lee, H. M. Kim, and S. R. Ha, 2010: Application of SWMM for evaluating NPS reduction performance of BMPs. Desalin. Water Treat., 19, 173-183, doi: 10.5004/dwt.2010.1910. [Link]

May, D. and M. Sivakumar, 2012: Prediction of long-term urban stormwater loads at single sites. P.I.Civil.Eng. Wat. M., 166, 81-92, doi: 10.1680/wama.11.00038. [Link]

Mourad, M., J. L. Bertrand-Krajewski, and G. Chebbo, 
2005: Sensitivity to experimental data of pollutant site mean concentration in stormwater runoff. Water Sci. Technol., 51, 155-162.

Nakdong River Environment Research Center (NRERC), 2011: Research on Long-term Monitoring and BMPs for the Non-point Source Discharge, NIER, Korea, 65-371.

Park, H. M., Y. J. Kim, and S. O. Ko, 2009: Characteristics of particle size distribution and heavy metal concentration in pavement road runoff. J. Kor. Soc. Road Eng., 11, 141-149.

Park, Y. H. and S. S. Park, 2004: Development of non-point source pollution loading function based on rainfall intensity and land use type. J. Kor. Soc. Environ. Eng., 26, 1070-1078.

Prince George's County (PGC), 1999: Low-Impact Development Design Strategies: An Integrated Design Approach, Prince George's County, Department of Environmental Resource Programs and Planning Division,
Maryland, $150 \mathrm{pp}$.

Shin, S. M., 2011: Runoff characteristics and nonpoint source pollution loads in industrial area. Master Thesis, Chonbuk National University, Korea.

The Ministry of Environment (MOE), 2008: The Report on Monitoring and Maintenance of Non-Point Pollutants Treatment Facility in Han River Watershed, MOE, Korea, Appendix 1-3.

The Ministry of Environment (MOE), 2011: The Amendment to Guideline for Applying Biotope Area Ratio, MOE, Korea, 3 pp.

Yeongsan River Environment Research Center (YRERC), 2011: Research on Long-Term Monitoring and BMPs for the Non-Point Source Discharge, NIER, Korea, 29-80.

Yoon, S. W., S. W. Chung, D. G. Oh, and J. W. Lee, 2010: Monitoring of non-point source pollutants load from a mixed forest land use. J. Environ. Sci., 22, 801-805, doi: 10.1016/S1001-0742(09)60180-7. [Link] 